\title{
iFace: Facial Expression Training System
}

\author{
Kyoko Ito***, Hiroyuki Kurose **, Ai Takami ** and Shogo Nishida ** \\ * Center for the Study of Communication-Design, Osaka University, \\ ${ }^{* *}$ Graduate School of Engineering Science, Osaka University, \\ Japan
}

\section{Introduction}

Nonverbal information, such as that contained in facial expressions, gestures, and tone of voice, plays an important role in human communications (Kurokawa, 1994). Facial expressions, especially, are a very important media for visually transmitting feelings and intentions (Yoshikawa, 2001; Uchida, 2006). At least one study has shown that more than half of all communication perceptions are transmitted through visual information (Mehrabian, 1981).

However, the person transmitting a facial expression cannot directly see his or her own expression. Therefore, it is important to understand the expression being transmitted and identifying the target facial expression in order to ideally express it. Facial muscles play a critical role in human facial expressions.

Facial expression training has recently garnered attention as a method of improving facial expressions (Inudou, 2007; Inudou, 1997; COBS ONLINE, 2007; Practice of Facial Expression, 2007). In facial expression training, exercises are performed that target a specific part of the face and those facial muscles. The muscles used in facial expressions are strengthened by training and when the facial expression is softened, the ideal facial expression can be expressed. Facial expression training has effective applications not only in daily communications, but also within the realm of business skills and rehabilitation. Facial expression training can take multiple forms, one of which is a seminar style experience with a trainer. Another method uses self training books or information on the Internet to serve as a guide. Some seminars are very expensive, and time and space are restricted. Alternatively, in a self training venue, it is difficult to clearly see your target facial expression when alone, and to compare your ideal facial expression with the present one.

The aim of this study is the proposal of an effective expression training system using the computer to achieve the target facial expression. As an initial step, an interface to select the target facial expression is proposed. Next, the expression training system, including the target expression selection interface, is developed.

A previous study (Miwa et al., 1999), one that used a virtual mirror, developed a facial expression training system that created a support system for facial expression training by utilizing a computer. The virtual mirror study was a facial expression training system displaying a facial expression by emphasizing the person's features with a virtual mirror. This study, however, is different from the virtual mirror study because this study instead selects the target facial expression of an actual face. 


\section{A facial expression training system that achieves the target facial expression}

\subsection{Support process}

In this study, the following steps are taken within facial expression training to achieve the target facial expression.

1) The target facial expression is identified.

2) The current facial expression is expressed in an attempt to achieve the target facial expression.

3) The current facial expression is compared with the target facial expression.

4) The muscles used for facial expression are trained.

In this study, the above enumerated processes are supported by a computer. This study also aims to develop a facial expression training system that can achieve target facial expressions. A computer is utilized to support each process of this method as follows:

1) For support in making the target facial expression;

2) For support in recognizing the current expression;

3) For support in comparing the current facial expression with the target facial expression;

4) For support in understanding the facial expression muscles that require training to achieve the target facial expression.

A primary objective of this study is the first item, above, to support making the target facial expression, and a user interface is proposed to achieve this goal. A proposal for the user interface is described below.

\subsection{Support method}

In this study, the following parameters are observed in making the target facial expression:

(a) Your own face is used.

(b) Your target facial expression must correspond to the movement of a real human face, the expression which is achievable.

The first item above, (a), that the target facial expression be made by using a real face is important because each human face is different from the next one. Your facial expression corresponds to your facial features.

The second item above, (b), necessitates making the target expression one that can actually be anatomically expressed using your real face. It is also important to be able to naturally make a satisfactory target facial expression.

Using these parameters, a user interface to select the target facial expression is considered. In addition, the following two stage approach is considered so that the user may select a satisfactory target facial expression:

- First stage: Rough expression selection

- $\quad$ Second stage: Detailed expression selection

During the first stage, based on "Emotion Map" (as illustrated in Figure 1) (Kurose et al., 2006) in Figure 1 proposed in our previous study, an interface (as illustrated in Figure 2) is proposed. Such an interface protects the user from having to worry about details and allows the user to intuitively select the target expression.

As shown in Figure 2, the interface consists of six facial images, each displaying a different potential facial expression, all arranged around a big circle in the center (Schlosberg, 1952). These six images are designed to correspond with six basic facial expressions: pleasure, surprise, displeasure, anger, fear, and sadness. Additionally, it is possible to both mix expressions from two different images and choose an expression strength level by selecting a point on the circle at the center. 


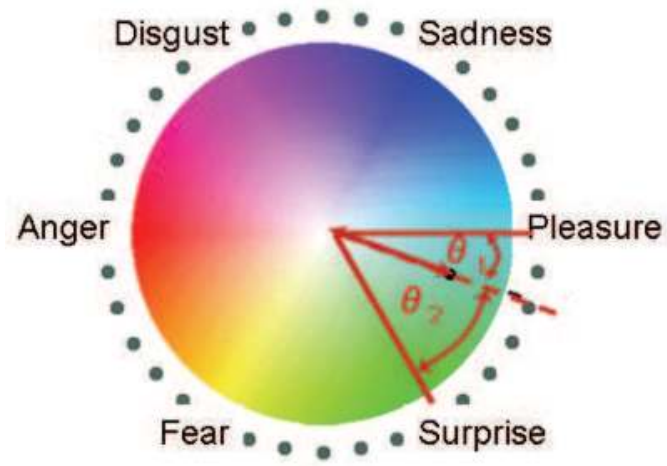

Fig. 1. Emotion Map

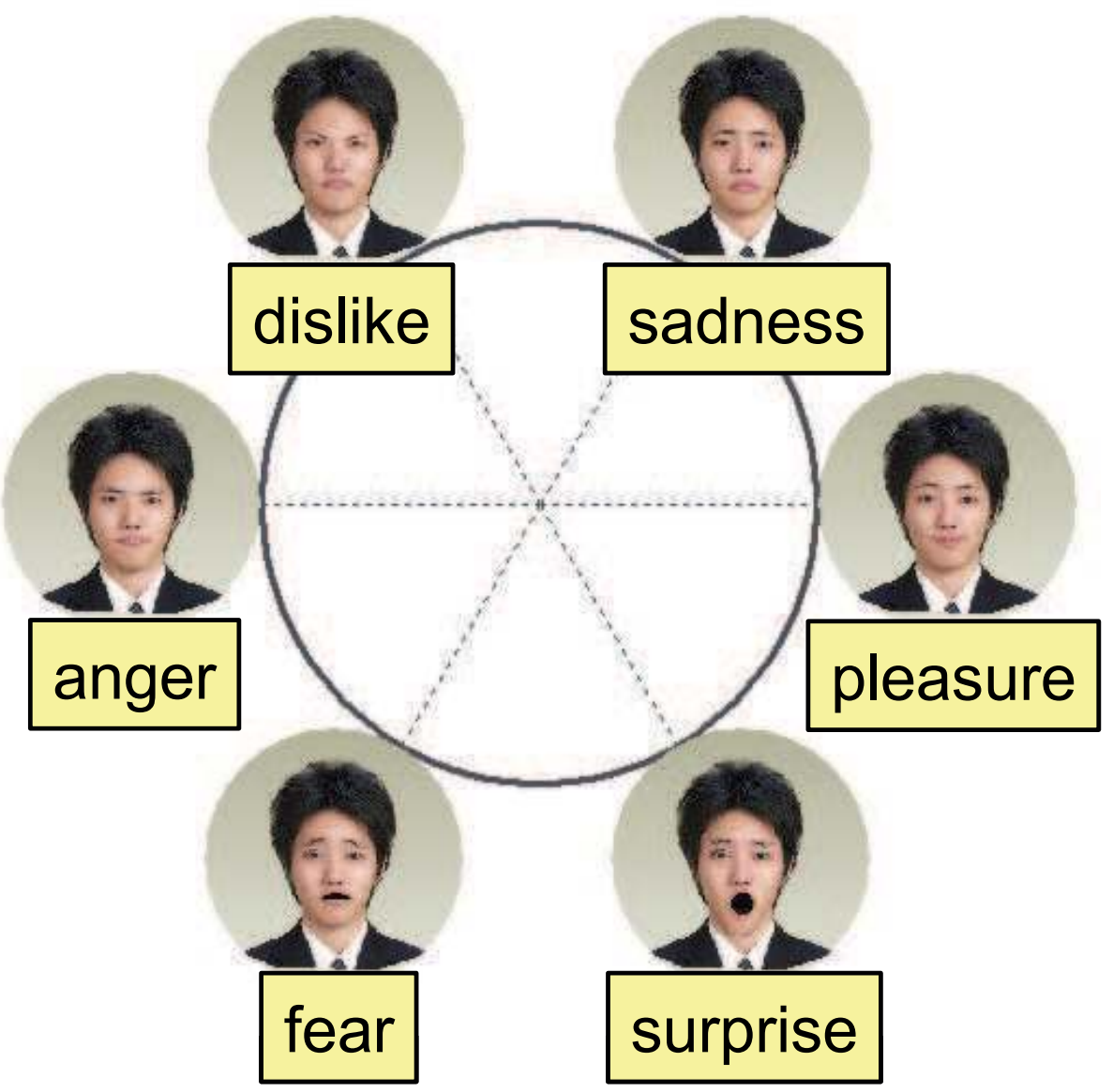

Fig. 2. Interface for selecting the target facial expression. 
In the second stage, for the user's satisfaction, another user interface is employed that enables a user to be able to control further details. In this stage, an action unit (AU), derived from Ekman et al's (Ekman et al., 1978) previous research about facial expression features is used. The elements of each feature as measured in AU can be thus established in detail. These features are comprised of eyebrows, eyes, cheeks, mouth, and mandibles. Action units of $3,5,2,10$, and 5 are used in each feature. In total, 25 kinds of AU are used.

\section{Design and development of the facial expression training system}

A facial expression training system including the above mentioned processes and the interface for selecting the target facial expression has thus been developed.

First, a personal computer camera is used to capture the current facial expression of the user. Figure 3 shows the hardware setup. Visual $\mathrm{C}++6.0$ is used as the software for the development of this system. In order to fit the user's face with a wire frame model, FaceFit (Galatea Project, 2007) is used. The facial expression training system developed (Parke, 1991; Waters, 1987) has been named "iFace." The following procedures are utilized in iFace:

1) User registration;

2) Selection of the target facial expression;

3) Expression of the current facial expression; and

4) Comparison of the current facial expression and the target facial expression.

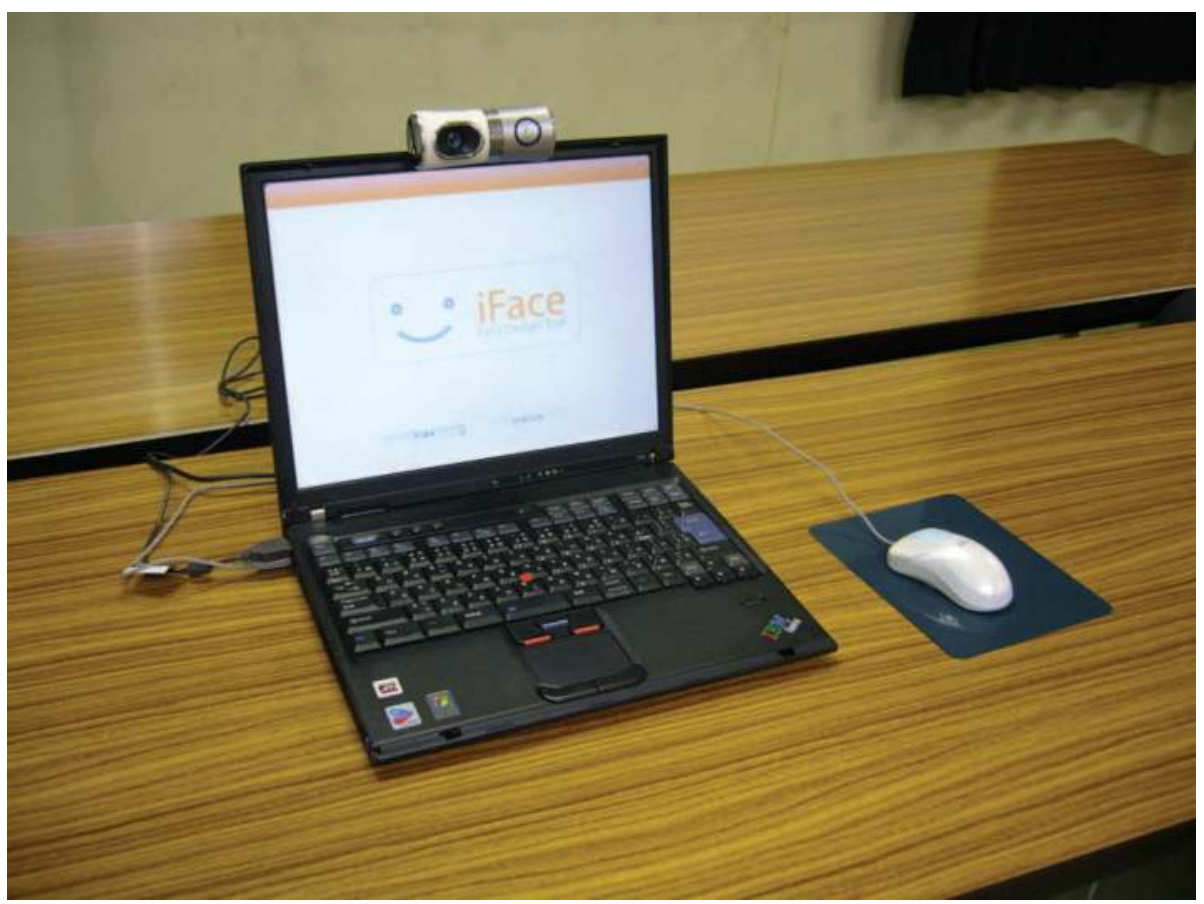

Fig. 3. Hardware setup

Figure 4 shows a screen of the user registration for the fitting. The screens for selecting the target facial expression with a rough setting and a detailed setting are shown in Figures 5 
and 6, respectively. Figure 7 shows the screen presenting the result of comparing the current facial expression with the target facial expression.

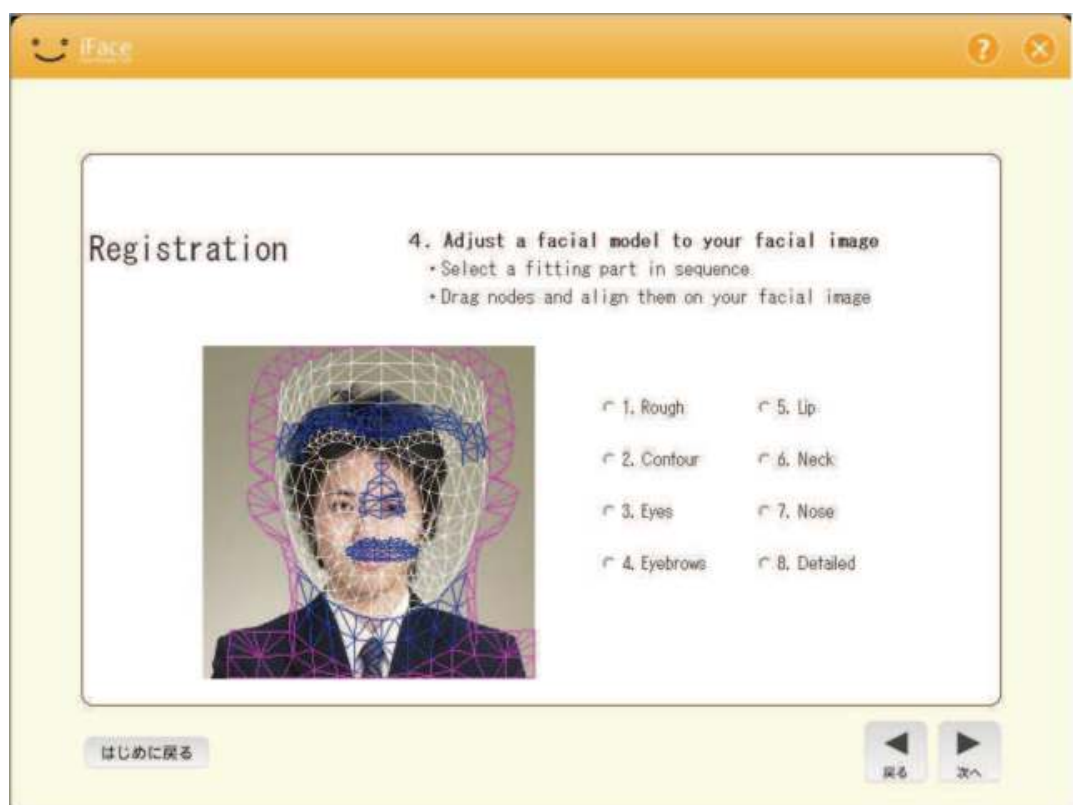

Fig. 4. A screen example of a user registration for fitting.

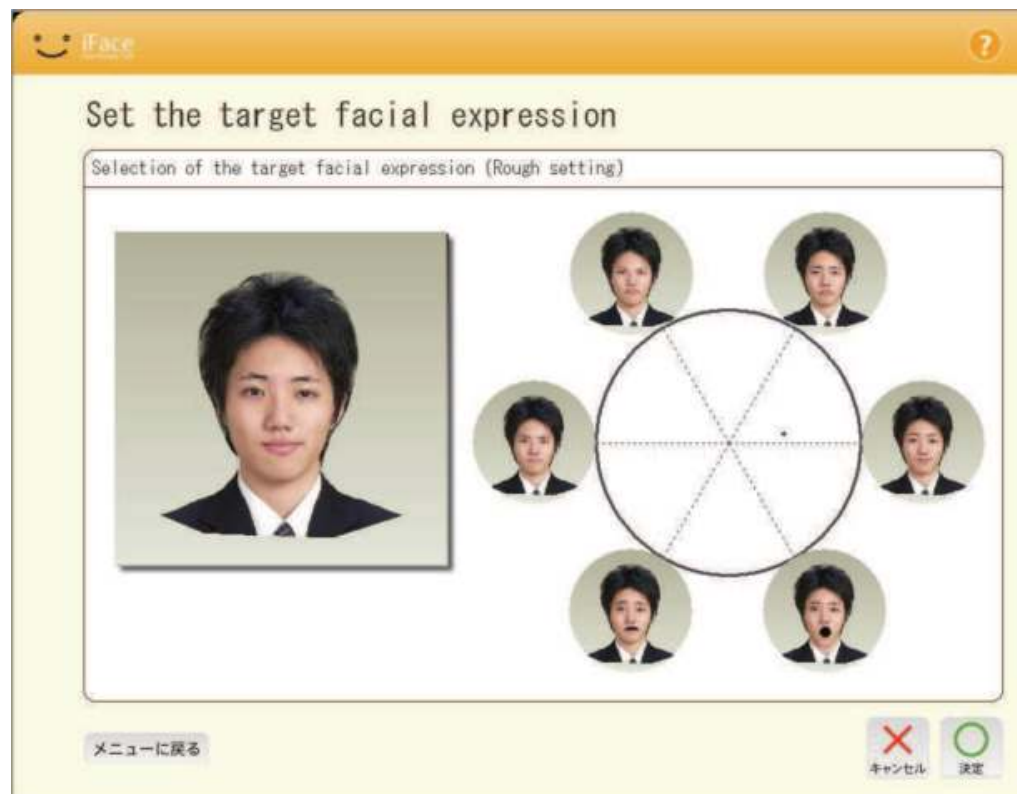

Fig. 5. Rough setting screen. 


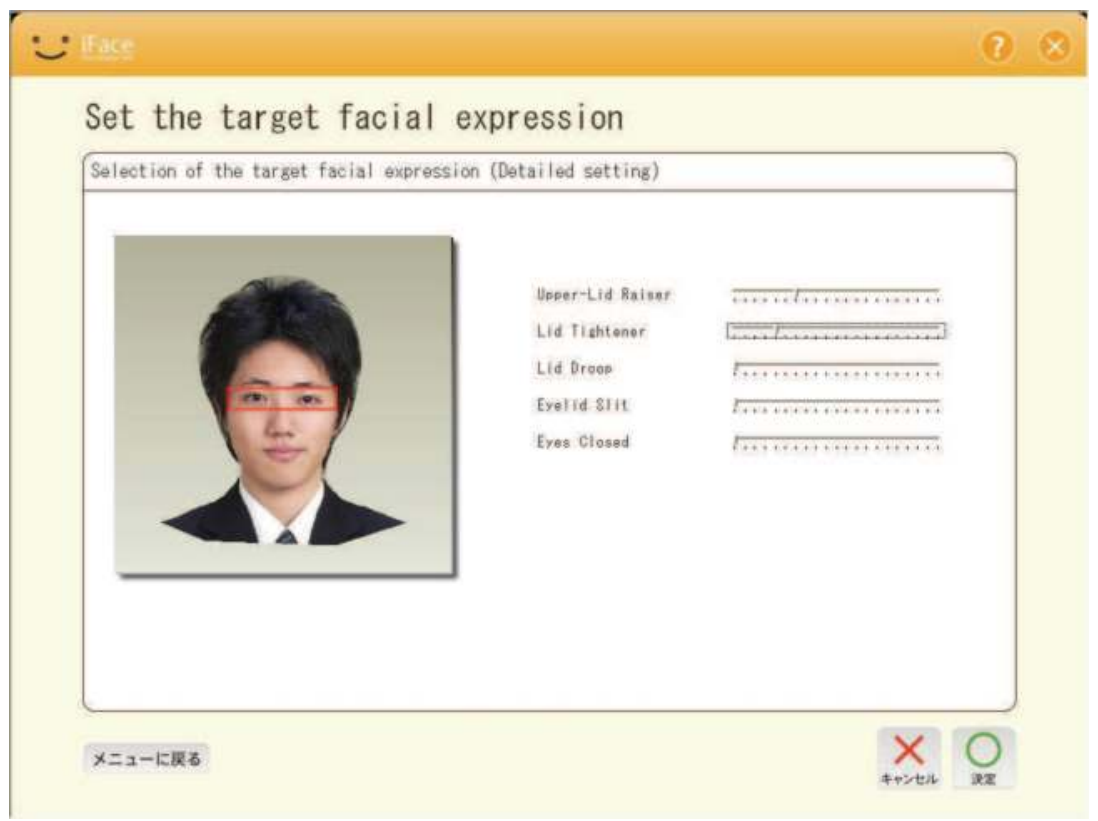

Fig. 6. Detailed setting screen.

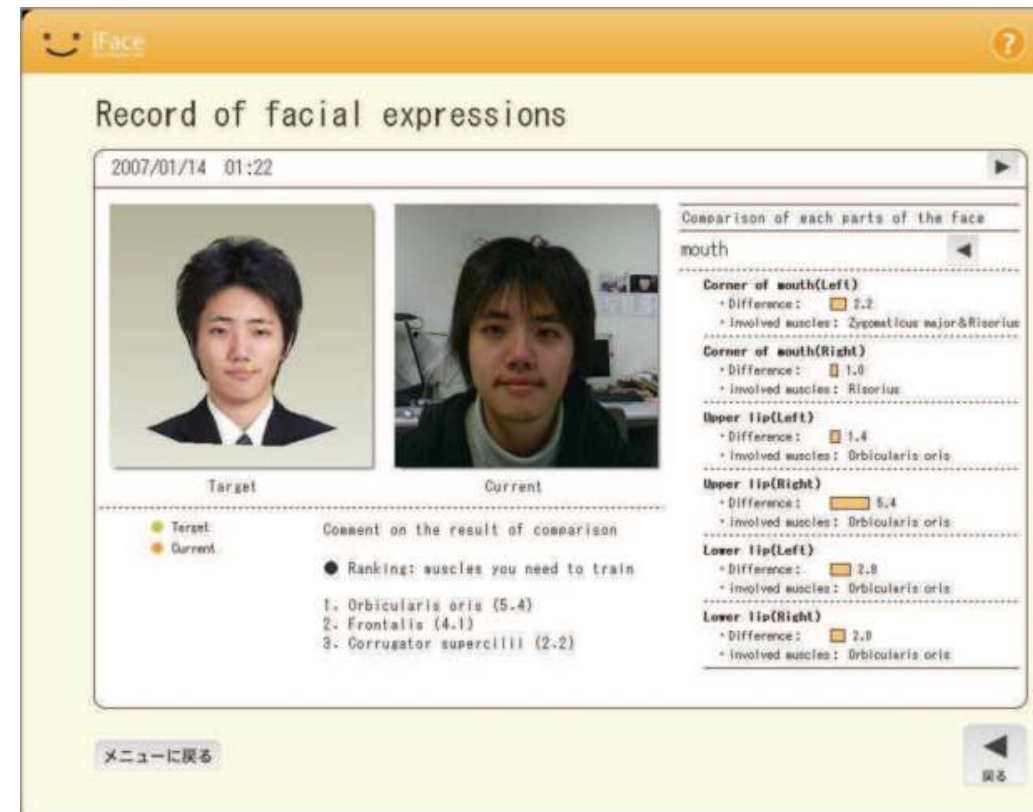

Fig. 7. An example of a screen showing a comparison between current and target 


\section{Evaluation of the facial expression training system}

\subsection{Purposes}

In order to examine the effectiveness of the target facial expression selection interface and the facial expression training system, an evaluation experiment was conducted. This evaluation experiment specifically aimed to examine the following points:

- The effectiveness of the target facial expression selection interface for a facial expression training system; and

- The potential for a facial expression training system.

\subsection{Methods}

A. Experimental procedure

1) The target facial expression is selected by the user by employing the facial expression training system.

2) A user attempts to enact the self-selected target facial expression, while the user's current facial expression is digitally captured.

3) The user's current facial expression is then compared with the target facial expression, and the results are presented.

Each user can select two target facial expressions. One target is the user's ideal smile, and the other is an elective choice by the user. The user's current facial expression is expressed three times in attempting to achieve each target expression. Therefore, a total of six expressions of the current facial expression are attempted.

B. Experiment participants

- 12 females (dentists)

C. Methods of analysis

The results of a questionnaire administered both before and after the experiment are used. In addition, data obtained during use of the facial expression training system are used.

\subsection{Results}

- Effectiveness of the target facial expression selection interface

Table 1 shows the results of the questionnaire regarding the effectiveness of the target facial expression selection interface. Answers to the questionnaire are ranked on a seven point

\begin{tabular}{c|l|c}
\hline$\#$ & Questionnaire item & Avg. \\
\hline 1 & $\begin{array}{l}\text { Did you satisfactorily achieve the target expression? } \\
\text { (Asked regarding the first target expression) }\end{array}$ & -0.3 \\
\hline 2 & $\begin{array}{l}\text { Did you satisfactorily achieve the target expression? } \\
\text { (Asked regarding the second target expression) }\end{array}$ & 1.7 \\
\hline 3 & $\begin{array}{l}\text { Was the facial expression selection interface both intuitive and } \\
\text { comprehensible? }\end{array}$ & 2.2 \\
\hline 4 & $\begin{array}{l}\text { Did you experience the synthesized facial expression in a way that felt } \\
\text { natural? }\end{array}$ & -0.3 \\
\hline
\end{tabular}

Table 1 Questionnaire results regarding the effectiveness of the target facial expression selection interface 
scale of +3 to -3 . Questionnaire results reflected an average satisfaction rating scores of -0.3 for the first target expression attempt (\#1) and 1.7 for the second target expression attempt (\#2). The questionnaire results also show that the satisfaction rating on the smile selection is lower than that of the elective choice expression.

In addition, the time required for selecting the target facial expression is shown in Figure 8 with separate amounts for a rough setting and a detailed setting at the smile selection. In a comparison between a rough setting and a detailed setting, it was demonstrated that there were many people who spent more time in a detailed setting.

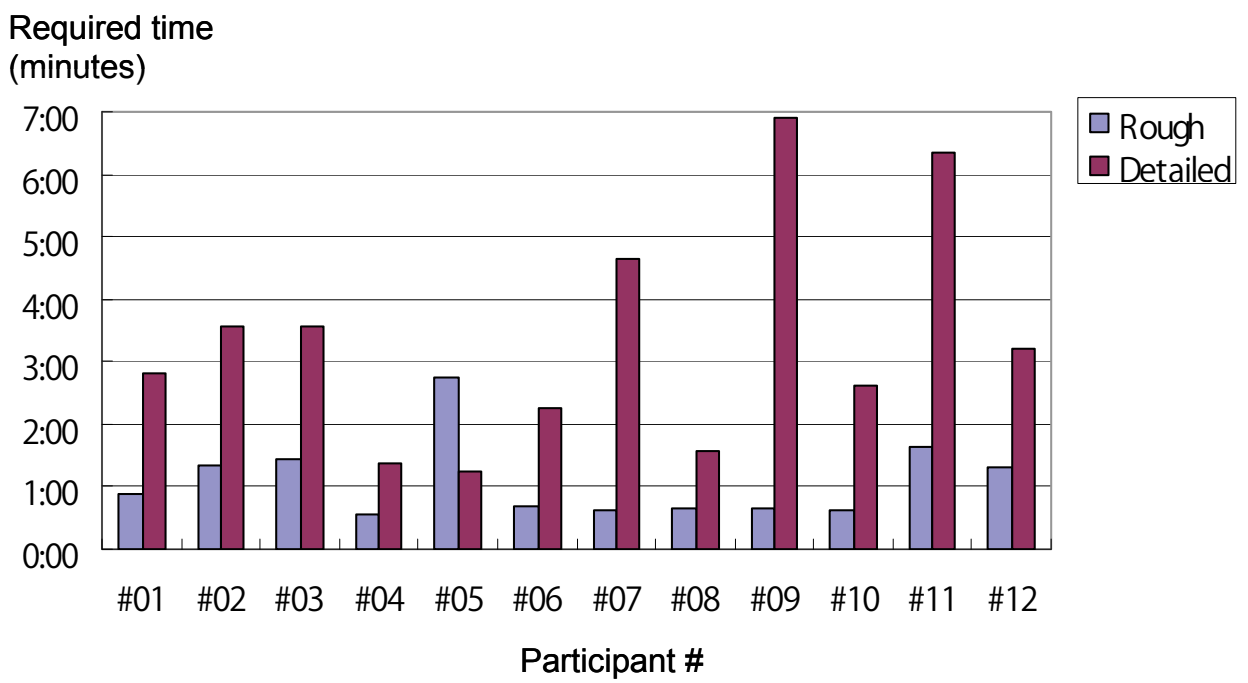

Fig. 8. The time required for rough and detailed selections of target facial expressions by each user.

\begin{tabular}{c|l|c}
\hline$\#$ & Questionnaire item & Avg. \\
\hline 5 & $\begin{array}{l}\text { Was the training method for deciding the target facial expression both } \\
\text { concrete and comprehensible? }\end{array}$ & 2.6 \\
\hline 6 & $\begin{array}{l}\text { Was it easy to express your actual expression by comparing the current facial } \\
\text { expression with the target facial expression? }\end{array}$ & 2.5 \\
\hline 7 & Would you want to use the facial expression training system daily? & 1.8 \\
\hline
\end{tabular}

Table 2 Questionnaire results regarding facial expression training system potential

- Facial expression training system potential

Table 2 shows the questionnaire results for facial expression training system potential. The questionnaire answers are ranked on a seven point scale of +3 to -3 . The results demonstrate that the facial expression training system was positively evaluated.

The following comments were obtained from comments written on the questionnaire: 
- I think that they can use it [a facial expression training system] to undergo rehabilitation for a paralytic face.

- My motivation for facial expression training increased when I made the target facial expression.

\section{Conclusion}

In this study, a target facial expression selection interface for a facial expression training system and a facial expression training system were both proposed and developed. Twelve female dentists used the facial expression training system, and evaluations and opinions about the facial expression training system were obtained from these participants.

In the future, we will attempt to improve both the target facial expression selection interface and the comparison of a current and a target facial expression. Successful development of an effective facial expression training system can then lead to actual and varied usage.

\section{References}

COBS ONLINE Business good face by facial muscles training (January, 2008). http://cobs.jp/skillup/face/index.html (In Japanese)

Ekman, P., and W. V. Friesen (1978). The Facial Action Coding System, Consulting Psychologists Press.

Galatea Project (January, 2008). http://hil.t.u-tokyo.ac.jp/ galatea/index-jp.html (In Japanese).

Kurokawa, T. (1994). Nonverbal interface, Ohmsha, Ltd., Tokyo (In Japanese)

Inudou, F. Facening Official Site (January, 2008). http://www.facening.com/ (In Japanese)

Inudou, F. (1997). Facening, Seishun Publishing Co., Ltd., Tokyo (In Japanese)

Kurose, H., Ito, K. and Nishida, S. (2006) A Method for Selecting Facial Expression based on Emotions and Its Application for Text Reading, Proc. of IEEE International Conference on Systems, Man, and Cybernetics(SMC2006), pp.4028-4033.

Mehrabian, A. (1981). Silent messages, Implicit Communication of Emotions and Attitudes, 2nd Ed., Wadsworth Pub. Co.

Miwa, S., H. Katayori and M. Inokuchi (1999). Virtual mirror: Proposal of Facial expression training system by face image data processing, Proc. 43th conference of the institute of system, control and information engineers, pp.343-344.

Parke, F. I. (1991). Techniques for facial animation, New Trends in Animation and Visualization, pp.229-241.

Practice of Facial Expression (January, 2008). http://www.nikkeibp.co.jp/style/biz /associe/expression/ (In Japanese)

Schlosberg, H. (1952). The description of facial expression in terms of two dimensions, Journal of Experimental Psychology, Vol.44.

Uchida, T. (2006). Function of facial expression, Bungeisha, Co., Ltd. (In Japanese)

Yoshikawa, S. (2001). Facial expression as a media in body and computer, pp.376-388, Kyoritsu Shuppan Co., Ltd. (In Japanese) 
Waters K. (1987). A Muscle Model for Animating Three dimensional Facial Expression, Computer Graphics, SIGGRAPH'87, Vol.2, No.4, pp.17-24. 


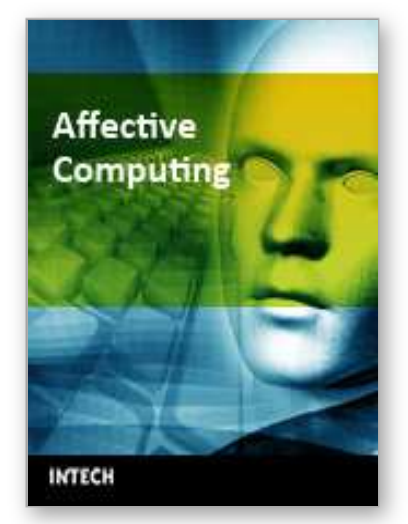

\author{
Affective Computing \\ Edited by Jimmy Or
}

ISBN 978-3-902613-23-3

Hard cover, 284 pages

Publisher I-Tech Education and Publishing

Published online 01, May, 2008

Published in print edition May, 2008

This book provides an overview of state of the art research in Affective Computing. It presents new ideas, original results and practical experiences in this increasingly important research field. The book consists of 23 chapters categorized into four sections. Since one of the most important means of human communication is facial expression, the first section of this book (Chapters 1 to 7) presents a research on synthesis and recognition of facial expressions. Given that we not only use the face but also body movements to express ourselves, in the second section (Chapters 8 to 11 ) we present a research on perception and generation of emotional expressions by using full-body motions. The third section of the book (Chapters 12 to 16) presents computational models on emotion, as well as findings from neuroscience research. In the last section of the book (Chapters 17 to 22) we present applications related to affective computing.

\title{
How to reference
}

In order to correctly reference this scholarly work, feel free to copy and paste the following:

Kyoko Ito, Hiroyuki Kurose, Ai Takami and Shogo Nishida (2008). iFace: Facial Expression Training System, Affective Computing, Jimmy Or (Ed.), ISBN: 978-3-902613-23-3, InTech, Available from: http://www.intechopen.com/books/affective_computing/iface_facial_expression_training_system

\section{INTECH}

open science | open minds

\section{InTech Europe}

University Campus STeP Ri

Slavka Krautzeka 83/A

51000 Rijeka, Croatia

Phone: +385 (51) 770447

Fax: +385 (51) 686166

www.intechopen.com

\section{InTech China}

Unit 405, Office Block, Hotel Equatorial Shanghai

No.65, Yan An Road (West), Shanghai, 200040, China 中国上海市延安西路65号上海国际贵都大饭店办公楼 405 单元

Phone: +86-21-62489820

Fax: +86-21-62489821 
(C) 2008 The Author(s). Licensee IntechOpen. This chapter is distributed under the terms of the Creative Commons Attribution-NonCommercialShareAlike-3.0 License, which permits use, distribution and reproduction for non-commercial purposes, provided the original is properly cited and derivative works building on this content are distributed under the same license. 